\title{
LIVROS ESCOLARES E MATERIAIS SUPLEMENTARES PARA O ENSINO DA LEITURA E DA ESCRITA NO ESTADO DO TEXAS (EUA): REFLEXÕES PARA PENSAR A ALFABETIZAÇÃO NO BRASIL ${ }^{1}$
}

\author{
SCHOOLBOOKS AND SUPPORT MATERIAL FOR TEACHING HOW TO READ AND TO WRITE IN \\ THE STATE OF TEXAS (USA): REFLECTIONS FOR BRAZIL
}

Eliane Teresinha Peres

Universidade Federal de Pelotas eteperes@gmail.com

\section{RESUMO}

Neste texto são apresentados alguns dados de pesquisa acerca dos livros escolares (didáticos e literários) e dos materiais suplementares produzidos e usados no estado do Texas, Estados Unidos, para o ensino da leitura e da escrita. O objetivo principal é, com isso, problematizar alguns discursos correntes no Brasil, em especial aquele que referencia o uso da instrução fônica naquele contexto. Os resultados da investigação evidenciaram que, embora a instrução fônica seja parte do programa escolar estadunidense, ela está sempre associada ao texto, literário ou informativo. Nesse sentido, são apresentados três aspectos constatados nos materiais instrucionais e nas salas de aula do contexto pesquisado: 1) a centralidade do livro e o foco no texto; 2) a recorrência do uso da palavra no processo de alfabetização; 3) a presença dos exercícios fônicos trabalhados no "contexto do texto".

Palavras-chaves: alfabetização; livro didático; livro literário; Estados Unidos; Brasil

\begin{abstract}
This paper presents research data on schoolbooks (textbooks and literature books) and support material produced and used to teach how to read and to write in the State of Texas, United States. Our main goal is to reflect on certain prevalent arguments in Brazil, especially those based on the use of phonics instruction in the United States. The results of our research show that even though phonics instruction is a part of the schooling program in the United States, it is always associated with texts, either literary or informative. We present three aspects observed in instructional material and in classrooms: 1) the focus on books and on text; 2) the recurrence of the use of high-frequency sight words; 3) the presence of phonics in the "context of a text".
\end{abstract}

Keywords: reading instruction; textbooks; literary books; United States; Brazil

\footnotetext{
1 A escrita deste artigo decorreu de pesquisa realizada entre os meses de agosto e dezembro de 2018, financiada pela Fulbright no contexto do Fulbright Visiting Scholar Program. Sou grata à instituição referida e igualmente à University of Texas at San Antonio, UTSA, USA, que me recebeu durante a estadia da concessão da bolsa de pesquisa. Contudo, as reflexões aqui descritas pautam-se, também, em outra experiência e em estudos feitos nos Estados Unidos. Trata-se do pós-doutoramento realizado durante um ano (2011-2012), na University of Illinois at Urbana-Champaign, UIUC, USA, com bolsa CAPES, instituição a qual sou igualmente grata pela oportunidade.
} 


\section{Introdução}

Há no Brasil, por vezes, um discurso corrente de que os chamados países desenvolvidos, incluído neles os Estados Unidos, alfabetizam suas crianças com mais rapidez e eficiência fundamentalmente porque usam o método fônico - aquele cuja base é a instrução sistemática da relação fonema-grafema - no ensino da leitura e da escrita. O objetivo principal das reflexões deste artigo é justamente problematizar essa afirmativa e argumentar que tal asserção é redutora, limitada e insuficiente.

Para o caso estudado, o do estado do Texas, foram coletados e analisados materiais didáticos, além de realizadas visitas técnicas e observações em salas de aulas de escolas elementares (Elementary Schools, que atendem do Kindergarten - Pré escola - ao $5^{\circ}$ ano) da cidade de San Antonio (Texas, USA) ${ }^{2}$. O presente artigo resulta dessa experiência. Contudo, as reflexões feitas aqui estão circunscritas aos materiais de ensino da leitura e da escrita, em especial aos livros de Linguagem e aos literários, dos dois primeiros anos escolares (Kindergarten, classes de crianças de 5 anos) e $1^{\circ}$ ano $\left(1^{\text {st }}\right.$ grade). Embora o programa de ensino da leitura e da escrita se estenda ao longo dos seis anos da escola elementar e seja considerado um continuum, acredita-se que os exemplos das duas primeiras séries sejam suficientes e esclarecedores ao propósito estabelecido.

Assim sendo, é preciso enfatizar que, diferentemente do contexto brasileiro, há uma compreensão no âmbito da educação norte-americana de que a alfabetização das crianças, o ensino inicial da leitura e da escrita, não se circunscreve a uma ou duas séries específicas, mas se estende ao longo dos seis anos da escolarização primária. Além disso, é preciso ter em mente que crianças em diferentes níveis de leitura e de escrita convivem conjuntamente nos mesmos anos escolares. Dessa forma, um aluno da Kindergarten (5 anos) pode ter um nível inicial de leitura (apenas conhecer as letras) ou avançado (ler com fluência), sendo isso igualmente válido para qualquer outra série/ano escolar. Os níveis de leitura e de escrita não retêm as crianças nos anos escolares, mas são trabalhados paulatina e individualmente ao longo da escolarização.

Além disso, diferentemente do caso do Brasil, não é o método de ensino que está em evidência nas discussões estadunidenses neste momento. Embora historicamente houve uma disputa entre os chamados Método Fônico (Phonic Word Method) e Método da Palavra/Global (Whole Word Method) a centralidade atual do debate no caso dos Estados Unidos é acerca de quais habilidades são necessárias desenvolver no ensino da leitura e da escrita e quais estratégias empregar para isso ao longo da escola elementar, especialmente considerando a heterogeneidade dos níveis de aprendizagem das crianças em uma mesma turma.

Para o caso do Texas, como para o de outros estados americanos, o desafio na alfabetização das crianças tem uma especificidade: o ensino da leitura e da escrita para alunos não falantes do inglês, via de regra, falantes do espanhol. Assim, o bilinguismo, com o ensino do inglês aos não falantes dessa língua e a manutenção da língua materna, ou mesmo o ensino do espanhol para os monolíngues em inglês, é um dos maiores desafios da alfabetização naquele contexto.

A perspectiva adotada é a da escola dual, do ensino dual da língua, ou seja, aquela em que as crianças - bilíngues e monolíngues - aprendem todas as matérias escolares nas duas línguas. Nesse sentido, vê-se classes em que crianças falantes apenas de inglês convivem e aprendem com crianças falantes apenas do espanhol ou de ambas as línguas.

2 San Antonio é a sétima cidade mais populosa dos Estados Unidos e a segunda mais populosa do Texas, com mais de 1,5 milhão de habitantes. Fundada por missões espanholas no século XVIII, é a cidade mais antiga do estado. O Texas foi durante muito tempo parte do antigo território espanhol, pertenceu também ao México e foi uma república independente entre os anos de 1836 e 1846. Assim, a cidade e as ruínas das missões espanholas são uma referência importante da história do Texas e de toda a região. Para saber mais consultar https:// www.sanantonio.gov e https://en.wikipedia.org/wiki/San_Antonio

3 Ver para isso o clássico estudo de Kim (2008) sobre Reading Wars. 
Embora haja versões em inglês e em espanhol para todos os livros didáticos e materiais suplementares em circulação nas escolas texanas, tanto os do aluno quanto os do professor, para este artigo e para o propósito do texto foram considerados apenas os livros em inglês, que serão referidos a seguir, para, na sequência, apresentar três aspectos evidenciados nos materiais instrucionais para o ensino da leitura e da escrita: 1) a centralidade do livro e o foco no texto; 2) a recorrência do uso da palavra no processo de alfabetização; 3) a presença dos exercícios fônicos trabalhados no "contexto do texto".

\section{Livros escolares e materiais suplementares produzidos e utilizados no estado do Texas (EUA): algumas considerações ${ }^{4}$}

Cabe ressaltar inicialmente que livro didático tem, no contexto norte-americano, um conceito e um uso mais alargados se comparado ao caso do Brasil. Textbook é o livro escolar destinado a todos os níveis de ensino, do Kindergarten à Universidade. Não há, nessa constatação, nenhuma novidade, especialmente considerando a advertência de Choppin (2009, p. 19), de que em se tratando de livro didático "tudo parece ser uma questão de contexto, de uso, até de estilo". Contudo, para o caso da escola elementar norte-americana, o livro didático de uso do aluno não tem valor senão agregado aos materiais suplementares que o acompanham, como, por exemplo, os livros literários, chamados de Small Books (Livros Pequenos), os jogos, os cartões de tamanho variados, os cartazes, os livros de exercícios, os materiais on-line, os Cds, as versões em áudio (Interactive Student Books), os guias para professores etc ${ }^{5}$.

A principal razão disso é especialmente o método de ensino adotado nas primeiras séries: o de pequenos grupos (Small Groups) 6 . Via de regra, a professora ensina os alunos considerando os diferentes níveis de domínio do conteúdo - no caso aqui em questão, da leitura. Os alunos são reunidos em pequenos grupos (enquanto os outros trabalham autonomamente em outras atividades variadas, de outras disciplinas inclusive) e o ensino é feito com material específico para o nível de domínio da leitura do grupo que está sendo ensinado. Daí o valor dos Small Books: livros literários classificados em níveis e que variam pela quantidade de textos, desde aqueles com apenas imagens, passando pelos livros com uma sentença por página até livros com textos mais longos e complexos. Para cada grupo, inclusive de uma mesma sala de aula, são apresentados livros com níveis de complexidade textual diferenciado.

Nesse sentido, não é demais afirmar que o livro de ensino da leitura é, por excelência, na escola norte-americana, o livro literário. E há centenas deles nas escolas: nas salas de aula, nas bibliotecas e nas salas de recursos didáticos das professoras. Assim, os Distritos Escolares ${ }^{7}$ e os professores, ao escolherem e comprarem materiais instrucionais, como são chamados, não consideram (ou consideram

4 Destaca-se que a produção, a compra e a adoção de livros escolares no caso dos Estados Unidos são descentralizadas, ou seja, feita no âmbito dos estados.

5 No processo da pesquisa não foi possível adentrar nos aspectos referentes aos montantes de valores desses materiais. Contudo, não é desproposital afirmar que se trata de um negócio milionário no país. Ainda nos anos de 1970, Karlin (1973, p. 176) afirmou que "instructional materials are a big business!", ou seja, a afirmativa é a de que os materiais de ensino são um grande negócio nos Estados Unidos. O autor destaca as relações estabelecidas nesse mercado, que envolvem, pelo menos, as grandes corporações industriais, as editoras e os compradores desses materiais.

6 O princípio da escola moderna, "ensinar tudo a todos como se fosse um só", tem pouco ou quase nenhum sentido na escola contemporânea nos EUA.

7 A organização do ensino nos Estados Unidos é descentralizada. Os Distritos Escolares são responsáveis pela administração das escolas públicas. Cada cidade possui Distritos que agrupam números variados de escolas (de três ou quatro escolas até mais de cem). Os Distritos Escolares são formados considerando muitas variáveis como, por exemplo, a região geográfica e o número de habitantes de uma dada região da cidade. Cada Distrito Escolar tem orçamento próprio e é responsável pela compra, adoção e distribuição dos materiais instrucionais para as escolas sob sua responsabilidade, a partir de uma extensa lista preparada e divulgada anualmente pelo State Board of Education, equivalente a uma Secretaria Estadual de Educação. 
muito pouco, na realidade) os livros didáticos, ou os livros de textos, mas sim o conjunto dos materiais didáticos, que são muitos, tanto para os alunos, quanto para os professores ${ }^{8}$. Assim sendo, nos Estados Unidos, talvez mais do que em outras realidades, "o livro didático [...] não tem mais existência independente, mas torna-se um elemento constitutivo de um conjunto multimídia" (CHOPPIN, 2004, p. 553).

Assim, pode-se dizer que no supracitado país de um modo geral, e no estado de Texas em específico, 'um livro didático não é só um livro'. Por vezes, a versão do aluno do livro didático é a menos utilizada e, talvez, a menos importante, uma vez que os materiais suplementares, pela sua natureza e pelo método pedagógico utilizado - instrução em pequenos grupos - tem mais valor, importância e uso.

Além disso, para o caso estudado, o(s) livro(s) de Linguagem do aluno, tanto do Kindergarten quanto do $1^{\circ}$ ano (1st Grade), por exemplo, de fato não se trata $(m)$ de um livro, mas de uma série de livros. No primeiro caso, o exemplar do aluno do livro didático tem pelo menos dois volumes (K1; K2), além dos volumes do Practice Book (livro de exercícios); e no segundo caso, do $1^{\circ}$ ano, geralmente são seis volumes, chamados de Unidades (Unit 1, Unit 2, Unit 3, Unit 4, Unit 5, Unit 6)9. Em geral, cada Unidade (livro) tem cinco lições (Lesson), totalizando, assim, 30 lições em um mesmo livro.

Destaca-se que esses livros são de capa dura, com papel do tipo couchê e não são consumíveis. Já os Practice Books - ou também chamados de Skills Books, Practice Workbooks, Writing Workbook10 - são consumíveis, de capa e papel simples, muitas vezes descartáveis, o que facilita o trabalho, uma vez que as professoras, em geral, apreciam essa técnica, de solicitar aos alunos que descartem as folhas dos livros consumíveis e trabalhem autonomamente com elas, podendo solicitar que diferentes alunos ou um grupo deles destaquem folhas e lições diferenciadas ou até de livros de disciplinas diferentes. Nesse sentido, nem todos executam a mesma atividade ao mesmo tempo.

Sobre os livros de Linguagem, ressalta-se que a existência da série de livros (séries graduadas), incluíndo os do professor, são uma prática histórica nos Estados Unidos. Em seu estudo, Venezky (1987, p. 250) revela que durante a última década do século XVIII e primeiro quartel do século XIX, com a expansão da escola pública e com a permanência das crianças por mais tempo na escola, uma série de livros para o ensino da leitura começou a aparecer no contexto norte-americano. Em relação aos manuais do professor, que acompanham esses livros e que existem até hoje em grande quantidade, formatos, orientações e perspectivas, o autor supracitado indica que:

Uma das grandes ironias no desenvolvimento dos modernos livros de ensino da leitura é que, à medida que os professores recebiam mais e mais treinamento no ensino da leitura, tanto na formação inicial, quanto continuada, os autores de textos de leitura assumiam que os professores sabiam cada vez menos e expandiam os manuais do professor e as instruções do livro de texto (VENEZKY, 1987, p. 252) ${ }^{11}$.

Essa expansão é facilmente perceptível e visível quando se visita escolas, salas de aulas, bibliotecas e acervos de livros didáticos: os guias de orientação para o trabalho do professor se multiplicam expressivamente e são bastante variados quanto à forma e ao conteúdo. São complexos e detalhados e existem para as diferentes disciplinas, ou, por vezes, para unidades ou conteúdos específicos.

8 Student Books, Teacher Version, Teacher Guide, Literacy Guide, Weekly Lesson Resources, Ready-Made Work Station, Audio Version Digital, Interactive Student Books, Work Books, Skill Books, Practice Books, Spelling Books, Decodable Practice Readers, Write Source, Dictionaries, Flash Cards, Retelling Cards, Picture Cards, Phonics Picture Cards, Rhyme Cards, Instructional Cards Kit etc.

9 Para o caso do $2^{\circ}$ ano (2sd Grade) são dois livros (Unit 1, 2.1; Unit 2, 2.2), para o $3^{\circ}$ ano (3rd Grade) idem (Unit 1; 3.1; Unit 2, 3.2), já para o $4^{\circ}$ e $5^{\circ}$ anos (4th 5th Grades) é apenas um livro, tendo muito mais páginas nesse caso.

10 Os Practice Books são referentes a cada um dos Textbooks, ou Unit, mas pode haver ainda, por exemplo, Phonics/Spelling Practice Book, Grammar Practice Book, Handwriting, entre outros. Ou seja, cada um deles é utilizado para desenvolver determinada habilidade (skill). Nesses casos, trata-se, de fato, de livros consumíveis, com atividades para os alunos desenvolverem.

11 Todas as traduções das citações são de minha reponsabilidade. 
No que tange ao conjunto de livros-texto para ensino da leitura, há um conceito que precisa ser compreendido para a realidade tratada, o de Basal Reading Materials, que é associado a uma prática de ensino da leitura e a uma perspectiva teórica cuja centralidade é o desenvolvimento de habilidades (skills) de forma progressiva.

Sobre os Basal Reading Materials, Herrick (1973, p. 150) discute o conceito afirmando que, embora a definição possa ser complexa e múltipla, a mais usualmente aceita é aquela que se refere à série de livros especialmente preparados para cada etapa sucessiva do desenvolvimento da leitura. Em outras palavras, são os livros (e os materiais que os acompanham) que contém os programas de leitura para os leitores em fase inicial da aprendizagem.

Nesse sentido, segundo o autor, Basal Reading Materials tornou-se sinônimo de série de livros graduados e há uma relação direta entre eles, as habilidades e os conhecimentos que devem ser ensinados e desenvolvidos com os alunos no que tange à leitura oral e silenciosa. Basal Reading Materials seriam, por definição, aqueles materiais feitos para desenvolver os hábitos e as habilidades consideradas essenciais e fundamentais no ensino da leitura.

Assim é que as séries de livros trazem inscritas em suas páginas os programas, as propostas, as perspectivas do ensino da leitura e da escrita. Analisar, pois, os livros produzidos no e para o Texas permite, portanto, compreender as propostas oficiais de ensino vigentes naquele estado. Associado a isso, considerou-se, também, para expor o que se segue, as visitas e as observações feitas em duas escolas e o documento curricular do estado do Texas, o TEKS (Texas Essential Knowledge and Skills), aprovado em 1998, pelo State Board of Education. O TEKS, currículo oficial do estado, inclui os conteúdos e as orientações de ensino de Matemática, Linguagem, Ciências e Estudos Sociais ${ }^{12}$.

\section{A centralidade dos livros e dos textos literários e informativos no contexto da alfabetização nos Estados Unidos}

No contexto das políticas e das práticas de ensino da leitura e da escrita das escolas norte-americanas, a compreensão, a fluência, o desenvolvimento do vocabulário e do trabalho de pensamento (denominado geralmente de Making Connection nos livros didáticos) são habilidades centrais. As consciências fonológica e fonêmica e a relação sons-letras (phonics) estão associadas a estas habilidades.

Segundo as orientações do TEKS (2017), os domínios da linguagem são o ouvir, o falar, o ler, o escrever e o pensar, que devem ser desenvolvidos de forma integrada através dos sete pilares que sustentam as habilidades linguísticas fundamentais: compreensão; resposta; múltiplos gêneros; finalidade do autor; composição; investigação e pesquisa.

Em relação à compreensão, segundo Venezky (1987), as estratégias para o ensino da mesma desenvolveram-se muito lentamente ao longo do século XX e somente alguns poucos métodos inovadores de ensino de compreensão textual foram incorporados nas séries de livros de leitura até o final dos anos de 1940. É somente após isso, com especial ênfase para os anos de 1960 e 1970, que se estabeleceu, conforme o autor, uma comunicação entre a psicologia cognitiva e o ensino de leitura; os livros passaram, então, a incorporar as noções mais populares dos estudos de compreensão e resolução de problemas.

12 O estado do Texas e mais oito estados americanos, Oklahoma, Florida, South Carolina, Nebraska, Minnesota, Indiana, Virgínia e Alaska, possuem currículos próprios para o K-12, ou seja, para o Kindergarten ao $12^{\circ}$ ano, Elementary e Middle School (equivalente à educação básica brasileira). Todos os outros 41 estados americanos adotam, desde 2010, um currículo nacional denominado Common Core State Standards (CCSS). Para o caso do Texas, todos os livros didáticos consultados, de Linguagem, de Estudos Sociais, de Matemática e de Ciências, têm como base os conhecimentos e habilidades prescritos no TEKS e, via de regra, trazem impresso nas capas essa referência Pode-se consultar o TEKS na íntegra em https://tea.texas.gov/index2.aspx?id=6148 
Dois exemplos, um de uma série de livros didáticos de Linguagem e outro de livros literários, servem aqui para o propósito deste trabalho, pois denotam a centralidade do livro e o foco no texto no ensino inicial da leitura no contexto estudado.

Primeiro, trata-se dos já referidos Small Books, que são justamente livros literários em pequeno formato, que existem às centenas nas escolas. São livros graduados (Leveled Readers) para diferentes níveis de leitor e de habilidade de leitura por série/ano escolar (Kindergarten, $1^{\circ}, 2^{\circ}, 3^{\circ}, 4^{\circ}, 5^{\circ}$ grades). Nesse sentido, há uma variação do número de palavras, havendo livros apenas de imagens e, também, aqueles com texto cujo número de palavras varia significativamente (de 07 até mais ou menos 3000 palavras), conforme a série escolar, as habilidades a serem desenvolvidas e os níveis de leitura dos leitores. Além disso, diversificam quanto ao gênero: ficção, não-ficção, fantasia, texto informativo, estudos sociais, ciências, ficção científica, ficção realista, história ficcional, humor, biografia; há uma variação também nas ilustrações, diferentes técnicas são identificáveis, bem como é recorrente o uso de fotografias nas ilustrações das histórias.

Enfatiza-se, ainda, que esses livros trazem na contracapa algumas informações: Estratégia (inferência, previsão, questionamento, verificação, visualização, análise, síntese, avaliação, monitoramento, esclarecimento, etc); Habilidade (estrutura da história, sequência de eventos, propósito do autor, características dos personagens, conhecimento de palavras, desenvolvimento do vocabulário, fluência, compreensão, precisão, conclusões, causa e efeito, detalhes, fato e opiniões, generalizações, etc); DRA - Developmental Reading Assessment, ou seja, a indicação (por número ou letra) de qual o nível e habilidade de leitura que o livro permite desenvolver, considerando os testes individuais das capacidades de leitura (DRA); Gênero (ficção, não-ficção, fantasia, texto informativo, estudos sociais, ciências, ficção científica, ficção realista, história ficcional, humor, biografia) e o número de palavras que o livro/texto contém.

Como em todos os casos, também os guias do professor detalham com precisão os passos para trabalhar com os Small Books: por exemplo, exploração do título e da imagem da capa; estudo detalhado das imagens e das ações feitas pelas personagens em cada página; leitura em voz alta pela professora e exploração de cada frase, do conteúdo em geral, do gênero, das personagens etc; estudo das palavras destacadas (Hight Frequency Words); leitura do texto pelos alunos, apontando as palavras em estudo; interpretação do texto (perguntas abertas, Personal Response); atividades de consciência fonológica e fonêmica (identificar oralmente cada palavra das sentenças, rimas, aliteração, listar outras palavras que rimam com as palavras em estudo, montar com alfabeto móvel as palavras destacadas, estudos da relação fonema-grafema, entre outras e variadas atividades de exploração das sentenças e das palavras); desenho; escrita etc.

Há um esforço e uma atenção em precisar em todo material didático - em uma espécie de "sincronia", de correlação direta - a gradação dos níveis de leitura, tanto nos livros-texto e literários dos alunos, quanto nos guias e manuais de professores (que existem em grande quantidade, como já enfatizado), nos currículos e nos testes padronizados.

Como se destacou, os guias do professor para exploração e estudo de cada livro didático e literário são precisos e detalhados, com o "passo a passo", incluindo as perguntas que as professoras podem fazer em cada etapa da exploração do livro e do texto, que devem ser examinados em todas as suas dimensões (incluindo uma exploração exaustiva das imagens, do autor, do ilustrador, das personagens, do gênero etc), para que então o estudo das sentenças, das palavras e as atividades de consciência fonológica e fonêmica possam ser feitas. Atividades dessa natureza foram recorrentemente observadas nas escolas pesquisadas. 
Reafirma-se, então, que cada livro é assim produzido para cada leitor específico (os iniciantes, os emergentes, os fluentes etc) e para o desenvolvimento das habilidades necessárias em cada momento de trabalho (desde o reconhecimento das características de um livro, passando pelo desenvolvimento das habilidades de consciência fonológica, como reconhecer fonemas, sílabas e rimas, até a fluência e a compreensão leitora). Cores, números e letras indicam, aos professores, a quem o livro é destinado (nível e estágio do leitor) e qual sua finalidade (quais habilidades desenvolve, quais atende no currículo oficial e quais mede nas avaliações padronizadas).

Essas informações são interessantes, mas o propósito principal desta seção é argumentar acerca da centralidade do livro e do foco no texto completo no processo inicial de ensino da leitura e da escrita. O primeiro exemplo, dos Small Books, teve esse próposito.

O segundo exemplo é dos próprios livros didáticos de Linguagem. Embora não sejam amplamente usados pelas professoras e professores, denotam uma perspectiva de ensino da leitura e revelam o quão importante é considerado o texto para a alfabetização das crianças. Em duas coleções pesquisadas, Texas Journeys, da Editora Houghton Mifflin Harcourt, e Texas Treasures, da Macmillan Mac Graw-Hill, há seis livros (Unit, como anteriormente mencionado) para o $1^{\circ}$ ano ( $1^{\text {st }}$ grade). Neles, como em todos os livros da escola elementar, há um fenômeno interessante que merece ser destacado: a reprodução de narrativas (histórias) completas.

Cada Livro (Unit) apresenta entre três e cinco histórias em cada lição, de diferentes autores e ilustradores (por vezes livros já existentes no mercado são reproduzidos na íntegra e o próprio livro - no formato Small Book - está disponível na sala de aula) e de gêneros diversificados. Nesse sentido, pode-se dizer que há "livros dentro dos livros". Diferentemente dos livros didáticos do Brasil, em que a literatura infantil é parcialmente reproduzida nas obras (parte de um texto literário), nos Estados Unidos as histórias integrais são reproduzidas nos livros, tanto o próprio texto, quanto as imagens.

Os exemplos aqui enfatizados referem-se aos livros de Linguagem, mas nos de outras disciplinas tal fenômeno também é recorrente, inclusive em livros de Matemática, em que a introdução de um conteúdo é dada a partir de uma história, algumas delas em folhas destacáveis para formar um livro independente.

Nos livros de Linguagem, cada história é precedida pelo estudo das palavras de alta frequência (Hight Frequency Words), do uso da palavra em contexto, em uma sentença (Context Card), sendo sucedido por atividades de comprensão, interpretação, oralidade, gramática, escrita etc.

Os livros se diferenciam muito dos livros didáticos do Brasil. O intuito é enfatizar, novamente, a centralidade do texto, em especial o literário, no processo de alfabetização. Destaca-se que não há apresentação de sílabas, letras ou fonemas isolados, tanto nos materiais didáticos, quanto em sala de aula. Essas unidades linguísticas estão sempre associadas a um texto completo ou a palavras de um texto, apresentado em diferentes suportes, de diferentes formas e com finalidades diferenciadas.

Nos livros pesquisados observou-se, como já foi enfatizado, que há em média cinco lições, cada uma com três histórias que são reproduzidas na íntegra. Isso significa que caso a professora optasse em usar esse livro na sua classe, ao completá-lo o aluno teria tido a oportunidade de ler, pelo menos, 15 histórias inteiras. Multiplicando isso por seis livros (Units), no caso das séries pesquisadas, o aluno teria contato ou teria tido a oportunidade de ler ou de ouvir ler em torno de 90 histórias completas. Mas a abundância de livros literários nas escolas permite ampliar esse número significativamente. Segundo as professoras observadas, com as quais dialogou-se, há a leitura diária e a exploração de, 
pelo menos, um livro literário na sala de aula e/ou na bilbioteca escolar. As leituras livres são, também, uma prática comum nas salas de aula.

Enfatiza-se que o texto completo reproduzido no livro didático sempre vem acompanhada do título em evidência e de uma pequena biografia do autor ou autores, do ilustrador ou do fotógrafo. A qualidade estética das imagens é um dos destaques desses livros. Outro destaque que merece ser feito é que essa mesma história vem também no formato de Small Book, ou seja, dos "pequenos livros" literários. Sendo assim, o aluno tem contato com a mesma narrativa em diferentes suportes.

As palavras a serem estudadas são destacadas e como se verá adiante trata-se de um procedimento central na alfabetização das crianças: o estudo da palavra em contexto de uso.

Uma consideração merece ainda ênfase: todos os textos completos e as imagens são reproduzidos nos materiais suplementares: em cartas, cartelas e cartazes, em cartões de tamanho variados, em livros de exercícios etc. A professora pode, então, trabalhar o texto de diversas formas e em diferentes suportes. Uma atividade bastante recorrente é a de solicitar aos alunos que recontem a história, a partir de cartões ou cartazes, apenas com as ilustrações (sequência) ou colocando as sentenças em ordem (no caso de materiais nos quais o texto está desmembrado em sentenças, ou seja, apresentadas separadamente, uma a uma).

Outro aspecto, dos muitos possíveis de se destacar nos livros didáticos e no conjunto de materiais suplementares, diz respeito aos gêneros textuais e literários: há uma importante e significativa variação deles nestes materiais, assim como as ilustrações, feitas com diferentes técnicas e tipos, alguns com fotografias, por exemplo, igualmente ao que se destacou dos livros literários, os Small Books.

Alguns exemplos de textos amplamente difundidos nos livros didáticos e, portanto, trabalhados nas salas de aula desde o Kindergarten, são, entre outros, de literatura contemporânea, de clássicos da literatura infantil, de história em quadrinhos, de biografias, de ficção científica, bem como os informativos de Estudos Sociais, de Ciências e até de Matemática, entre outros.

Sobre os textos e os livros informativos, é interessante destacar, conforme indica Venezky (1987), que foi no início do século XX que a "leitura da área de conteúdo", ou a leitura de textos com conteúdos de Ciência, Matemática, Estudos Sociais e outros materiais não literários (não ficcionais), foi descoberta no contexto norte-americano. Pode-se dizer que desde então tal perspectiva parece ter crescido consideravelmente e é possível perceber a partir da observação o quanto isso foi incorporado, tanto nas práticas de ensino na sala de aula, quanto nos próprios livros específicos de Linguagem e das outras disciplinas escolares.

As duas coleções pesquisadas, Texas Journeys, da Houghton Mifflin Harcourt, e Texas Treasures, da Macmillan MacGraw-Hill, revelam a tendência daquilo que no Brasil se convencionou chamar de livro informativo. A partir deles - com textos de Ciências, Estudos Sociais, Matemática -, também se ensina a ler, destacando as palavras e as unidades fônicas das palavras, sempre observando o contexto, qual seja, o texto. Nesse sentido, não há separação entre "textos para aprender a ler" e "textos para ler" ou "para aprender conteúdos de uma outra área de conhecimento", como, via de regra, é a tradição didático-pedagógica no Brasil.

Na sequência, destaca-se a importância do ensino da palavra que se expressa nos livros e nos materiais suplementares, consequentemente presente de forma recorrente nas salas de aula no contexto norte-americano. 


\section{A importância e a recorrência do estudo da palavra e do controle do vocabulário na alfabetização e nos materiais instrucionais do estado do Texas (EUA)}

Segundo Venezky (1987, p. 256), "o controle do vocabulário e a necessidade de repetidas exposições a novas palavras entraram lentamente na maioria das séries de livros didáticos de ensino da leitura em meados do século XIX", com ênfase para a repetição das mesmas palavras em diferentes lições, sendo que aquelas que eram consideradas mais difíceis apareciam ainda mais frequentemente. No entanto, segundo o autor, com a publicação do "Livro de Palavras do Professor (1921), de Thorndike, o controle do vocabulário do leitor pela frequência da ocorrência tornou-se um fetiche para o design de livros de leitura" (VENEZKY, 1987, p. 256).

Assim, historicamente, todas as séries - Basal Reading Materials - apresentam palavras para os alunos conhecerem e dominarem em cada lição. Um vocabulário selecionado com palavras de alta incidência (Hight Frequency Words) é comum nos livros norte-americanos, seja do passado, seja do presente. Trata-se de uma parte importante do programa de leitura. $\mathrm{O}$ uso da palavra como unidade fundamental de ensino também está associado à habilidade de desenvolvimento e ampliação do vocabulário ${ }^{13}$.

Tal abordagem aparece nas duas coleções pesquisadas, Texas Journeys, da Houghton Mifflin Harcourt, e Texas Treasures, da Macmillan MacGraw-Hill. Ambas revelam a importância da palavra no processo de ensino da leitura. Todas as lições apresentam as Words to Know, ou seja, as "palavras para conhecer", que variam em cada lição, entre duas no começo (livros do Kindergarten) até seis ou oito nos livros do $1^{\circ}$ ano. Além disso, elas são recorrentemente repetidas (Hight Frequency Words) em sentenças, textos e exercícios. Não apenas se repetem nas atividades do livro didático, mas igualmente nos materiais suplementares: nos livros literários (Small Books), nos livros de exercícios, nos cartões de diferentes tamanhos, nas cartas de gravuras etc.

Nos casos estudados, já na primeira lição do primeiro livro (Unit 1), por exemplo, aparecem, primeiramente, a lista de palavras a serem conhecidas e, na sequência, aplicadas em sentenças, no recurso denominado de Context Card. Trata-se da história em partes, que na continuidade das lições do livro são apresentadas, em diferentes páginas, na sua totalidade, sendo introduzida pelos dados do autor, ilustrador ou fotógrafo. Na reprodução integral da história, as palavras aparecem destacadas, cobertas com a cor amarela. Nesse sentido, apenas com o uso desse livro de Linguagem, a professora pode trabalhar com a palavra no contexto da sentença e no do texto. Pode-se dizer que a palavra aparece e reaperece, tanto no mesmo suporte, quando em diferentes suportes (Small Books, cartas, cartões, cartazes etc).

Considera-se que os exemplos mencionados são suficientes para o argumento que se quer apresentar, qual seja, o da centralidade e foco do texto na sala de aula e nos livros escolares e materiais suplementares. Além disso, destaca-se, novamente, que o formato, a estrutura e o conceito de livro didático são diferentes quando comparados aos do Brasil. Entender a alfabetização no contexto estadunidense significa entender essa diferença, além da necessidade de compreender a estrutura e o funcionamento escolar, os programas de ensino, os materiais didáticos e as práticas de sala de aula, entre outros aspectos.

Na sequência, serão feitas algumas considerações acerca da chamada instrução fônica presente nos materiais didáticos coletados e analisados, bem como se apresentará o exemplo de uma atividade acompanhada em sala de aula no que tange ao ensino da relação grafema-fonema.

13 Sobre a incidência da palavra em livros de ensino da leitura - primers - no contexto histórico estadunidense, ver Peres (2014). 


\section{Os exercícios fônicos como parte do programa de ensino da leitura e da escrita nos Estados Unidos}

Inicialmente vale destacar que, de acordo com a Internacional Literary Association(ILA, 2018, p. 2), phonics é o "estudo da relação entre os sons e as letras. Trata-se de um componente essencial do ensino e da prática de leitura e escrita nos primeiros anos da escola elementar". Ainda, segundo as orientações da ILA (2018), os exercícios fônicos devem ser parte de um programa abrangente de alfabetização, que inclui, também, o desenvolvimento da compreensão, do vocabulário, do pensamento, da fluência e da escrita.

É previsto no documento do TEKS (2017) que os alunos, já no primeiro ano de escolarização, no Kindergarten, devem desenvolver o conhecimento da estrutura da palavra através da consciência fonológica, dos exercícios fônicos, da morfologia.

Há livros específicos para o desenvolvimento das consciências fonológica e fonêmica. Todos eles com texto completo. Portanto, phonics (relação fonema-grafema) é ensinada, na escola norte-americana, no "contexto do texto". Para além disso, é um trabalho que se estende ao longo da escolarização elementar, não circunscrito apenas a uma ou duas séries iniciais.

Há livros específicos (também pequenos no formato) com essa finalidade, chamados Decodable (e há os Pre-Decodable, com apenas imagens ou uma frase por página), cuja ênfase são os exercícios fônicos, no "contexto do texto". Um exemplo de um texto de um desses livros é aqui reproduzido e dá uma ideia geral desse ensino: "I am Dan Cat. Dan Cat sat. I am Nan Cat. Nan Cat sat. Dan sat. Nan sat. Dan and Nan can play" (Decodable Readers. Around the Neighborhood, Houghton Mifflin Harcourt, 2010). O livro, indicado para o Kindergarten, tem nove páginas, incluindo a primeira com orientações do trabalho e da habilidade a ser desenvolvida, nesse caso o short a - palavras com a chamada "vogal curta", em inglês. Cada uma das sentenças aparece em uma página do livro, com belas ilustrações. Ao final há indicação dos exercícios a serem feitos: identificar as letras maiúsculas, identificar e ler os nomes próprios (dos gatos), dizer o nome de cada letra, identificar e destacar a "vogal a curta", short a (/æ/), escrever o seu próprio nome, identificar as letras maiúsculas e dizer o nome de cada uma delas, identificar as letras minúsculas, dizendo o nome dessas letras.

Assim, como se pode perceber com o exemplo apresentado, não se trata de textos "inventados", ou como se convencionou chamar no Brasil, "textos acartilhados", para o ensino de um fonema ou de famílias silábicas. São textos literários, via de regra, da literatura contemporânea ou textos "de conteúdo", com gradação de dificuldades (sentenças curtas até textos mais longos e complexos) que depois de lidos, discutidos e explorados, são o mote para as atividades phonics.

Para encerrar a seção e apenas a título ilustrativo, apresenta-se considerações acerca de uma aula de instrução fônica, acompanhada em uma escola em San Antonio, TX, em uma classe de segundo ano. Tal relato permite perceber a centralidade do livro e do texto no ensino da leitura e da escrita. Neste caso, o texto veio depois da intervenção da professora e de ampla discussão e exploração de palavras com os alunos: significados, usos, pronúncia, grafemas, fonemas etc.

A professora observada listou, no quadro, catorze palavras, verbos no passado, portanto com a terminação -ed (liked, por exemplo) e verbos que na língua inglesa representam ações contínuas no presente ou no passado, representados pelo sufixo -ing (making, por exemplo). Todo o tempo da lição, a professora reforçava os sons finais das palavras e sua forma de escrita, lendo as palavras, ou solicitando que um dos alunos lesse, e fazendo perguntas que supunham respostas das relações fonema-grafema. 
Após a exploração, que durou não mais do que 10 minutos, com os alunos sentados no chão, no tapete da sala (via de regra, onde se dão as lições coletivas nas escolas norte-americanas), a professora mandou que cada criança escolhesse um livro, lesse a história e procurasse as palavras terminadas em -ed e -ing, destacando-as. Logo depois, deveriam recontar a história a um colega referindo as palavras encontradas, seu significado e contexto de uso. Trata-se, então, de mais um exemplo da relação do texto com o ensino das unidades da língua. Sendo assim, é preciso ter em mente, quando se fala da instrução fônica, no caso da realidade do país, a centralidade dos textos, literários ou informativos, como reiteradamente aqui se destacou.

Para finalizar, enfatiza-se que pesquisar e procurar descrever e analisar esse variado e diferenciado material para ensino da leitura e da escrita produzido e usado no estado do Texas, permitiu algumas considerações que serão feitas a seguir, como finalização das problematizações propostas.

\section{Considerações Finais}

Interpretar realidades é uma tarefa bastante difícil e exigente, mas é própria e constitutiva da pesquisa e do pensamento científico. Contudo, vale a ressalva de que se analisar a nossa própria realidade (brasileira) já é um trabalho extremamente complexo, compreender e explicitar outras realidades é uma empreitada ainda mais árdua e laboriosa. A realidade não se mostra diretamente acessível, coerente e homogênea em nenhuma sociedade. É o trabalho de pensamento, reflexão e embasamento teórico que dá ao pesquisador a possibilidade de conhecer alguns aspectos dessa realidade. Para o caso da sociedade norte-americana, em especial da educação e da alfabetização naquele contexto, não é diferente.

Assim, não se pretendeu, com o presente artigo, apresentar "a realidade" sobre o ensino da leitura e da escrita ou sobre a escolarização primária nos Estados Unidos. Nem seria possível fazê-lo. Como toda a sociedade, a norte-americana é complexa, contraditória, hierarquizada, diferenciada e singular em alguns aspectos. Além disso, o país é extenso e com diferenças importantes do ponto de vista das regiões que se expressam também nas escolas. No caso da experiência acompanhada, em uma cidade de um estado do sul do país, San Antonio, no Texas, é preciso ponderar, pelo menos, alguns aspectos importantes: sua posição geográfica, sua história, o caráter multicultural, multiétnico e bilíngue daquela comunidade.

O que se pretende relembrar, portanto, é que não se compreende facilmente contextos tão complexos e plurais como esse referido. O que se almejou mostrar, de fato - para provocar o debate -, foi a dimensão redutora e limitada de determinados discursos que circulam no Brasil, especialmente de que o possível sucesso da alfabetização da população nos Estados Unidos estaria associado diretamente ao uso do método fônico. Aliás, uma primeira ressalva pertinente é justamente a de que a questão do método não está em evidência mais naquele contexto, parece ser um debate esgotado.

Para aquela realidade, há outros aspectos que precisam ser ressaltados, se existe de fato interesse e sentido em comparar ou tomar aquela sociedade e sua educação como referências para os discursos da/na alfabetização brasileira. Dentre eles está a constatação de que a escola pública, laica e gratuita ainda é um projeto social na sociedade norte-americana, mesmo considerando as muitas e variadas ações de enfraquecimento da educação pública naquele contexto ${ }^{14}$. E há diferenciais, quando comparada com a escola brasileira, que precisam ser igualmente enfatizados, pelo menos na realidade observada: a escola de tempo integral (via de regra, das 7 h30 às 15 h, com refeições);

14 Ver para isso, por exemplo, a experiência das charter schools (LUBIENSKI, 2013). 
a permanência da professora em uma mesma escola e em uma mesma série no ano letivo e em anos subsequentes; a qualidade dos prédios, da infraestrutura e de pessoal (professoras, assistentes sociais, psicólogas, terapeutas etc); a abundância de materiais didático-pedagógicos para alunos e professores; a qualidade, o tamanho, os acervos e os projetos nas bibliotecas escolares; as salas de atendimento aos alunos especiais; a perspectiva de ensino, dos pequenos grupos; a compreensão e a organização dos espaços e dos tempos escolares considerando a heterogeneidade das aprendizagens.

Certamente, outros aspectos poderiam ser salientados. O "olhar da estrangeira", contudo, não quer dar a impressão da ausência de problemas, quer chamar atenção, apenas, para o cuidado e a atenção de comparar aquilo que, por vezes, pode ser incomparável, ou de tomar uma dada experiência de forma descontextualizada, isolando fenômenos que só podem ser vistos conjunta e articuladamente.

A alfabetização e seu sucesso não dependem da adoção, tão somente, de um ou de outro método. Essa é, de fato, uma lição que o Brasil precisa aprender urgentemente. Aliás, que já deveria e poderia ter aprendido. E não são só as experiências externas que indicam essa necessidade. A própria história de nosso país aponta para o perigo "da visão única". Ao longo da nossa história e pelo menos desde o século XIX, de forma mais intensa, já se passou da defesa do método da soletração, ao fônico, ao silábico, ao global, ao da palavração, ao "construtivismo", construindo e produzindo "crenças" 15 em torno dos métodos de ensino da leitura e da escrita e seus possíveis "efeitos milagrosos". E o fracasso na alfabetização e na escolarização da população ainda é uma triste realidade a ser vencida. Acreditar que será possível reverter essa situação adotando um método único no país é, no mínimo, ingênuo e constrangedor. Usar a referência de outros países de forma descontextualizada é, também para dizer o mínimo, ausência de competência técnica, de limitações intelectuais e de capacidade de análise de realidade.

Definitivamente, a alfabetização e a escolarização norte-americana não se circunscrevem à adoção do método fônico, embora a instrução fônica seja parte do programa escolar estadunidense, ela está sempre associada ao texto, literário ou informativo, como procurou-se evidenciar no presente artigo.

Assim, acompanhar o trabalho de escolas no estado texano ${ }^{16}$ e coletar e analisar um conjunto variado e extenso de materiais instrucionais para o ensino da leitura e da escrita permitem as afirmativas e as reflexões feitas aqui, cujo intuito principal é o de fomentar o ainda urgente e importante debate sobre a alfabetização no Brasil.

\section{Referências}

AUGUST, Diane et. al. Texas Treasures. A Reading/Language Arts Program. New York, USA, 2011.

BAUMANN, James F. et. al. Texas Journey. Houghton Mifflin Haurcourt School Publishers. Orlando/ Florida, USA 2011.

CHOPPIN, Alain. O historiador e o livro didático. História da Educação, Pelotas: ASPHE, v. 6, n. 11, p. 5-24, jan./ jun. 2002.

CHOPPIN, Alain. O manual escolar: uma falsa evidência histórica. História da Educação. Pelotas: ASPHE, v. 13, n. 27, p. 9-75, jan./abr., 2009.

15 Ver para isso Peres (2017).

16 E antes disso, entre os anos de 2011 e 2012, no estado de Illinois, nas cidades "gêmeas" Urbana-Champaign. 
CHOPPIN, Alain. História dos livros e das edições didáticas: sobre o estado da arte. Educação e Pesquisa, São Paulo, v. 30, n. 3, p. 549-566, Dec. 2004. Availablefrom<http://www.scielo.br/scielo.php?script=sci_ arttext\&pid=S1517-97022004000300012\&lng=en\&nrm=iso >. accesson 07 Dec. 2018.

HERRICK, Virgil E. (With the assistance of Dan Anderson and Lola Pierstorff). Basal Instructional Materials in Reading. In: KARLIN, Robert (ed.). Perspectives on Elementary Reading. Principles and Strategies of Teaching. p. 176-183. New York: Harcourt Brace Jovanovich, Inc., 1973.

HOUGHTON MIFFLIN HARCOURT Around the Neighborhood, Decodable Readers, 2010.

INTERNATIONAL READING ASSOCIATION (IRA). Literacy Leardship Brief Explaining Phonics Instruction an Educator's Guide.2018.Disponível em https://literacyworldwide.org/.../ila-explaining-phonics-instruction-aneducators-guide. Acesso em 16, Dez., 2018.

KARLIN, Robert. Reading Materials: Rationale and Review. In: KARLIN, Robert (ed.). Perspectives on Elementary Reading. Principles and Strategies of Teaching. p. 176-183. New York: Harcourt Brace Jovanovich, Inc., 1973.

KIM, James S. Research and the Reading Wars. In: HESS, Frederick M. When Research Matters: How Scholarship Influences Education Policy. Harvard EducationPublishingGroup. Cambridge. MA, 2008.

LUBIENSKI, Christopher. Privatising form or function? Equity, outcomes and influence in American charter schools. Oxford Review of Education,39:4,498-13, 2013.

PERES, Eliane. Influências do pensamento norte-americano na produção de cartilhas para o ensino da leitura e da escrita no Rio Grande do Sul na década de 1960. In: MORTATTI, Maria do Rosário Longo; FRADE, Isabel Cristina Alves da Silva (Org.). História do ensino de leitura e escrita, métodos e material didático. Marília: Unesp, 2014. p. 93-120.

PERES, Eliane. 'A produção da crença': políticas de alfabetização no Brasil na última década (2006-2016). In: Marília Andrade Torales Campos \& Monica Ribeiro da Silva. (Org.). Educação, Movimentos Sociais e Políticas Governamentais. 1ed.Curitiba: ApprisEditora, 2017, v. 1, p. 29-43.

TEKS (Texas Essential Knowledge and Skills). English Language Arts and Reading, Kindergarten, Adopted 2017. State Board of Education, Austin, TX. Disponívelemhttps://tea.texas.gov/index2.aspx?id=6148. Acesso em06, Jun, 2019

VENEZKY, Richard L. A History of the American Reading Textbook. The Elementary School Journal, Vol. 87, No. 3, Special Issue: The Basal Reader in American Reading Instruction (Jan., 1987), pp. 246-265. Published by: The University of Chicago Press Stable URL: https://www.jstor.org/stable/1001175. Accessed: 11-11-2018 03:22 UTC.

Recebido em: 05/08/2020

Aceito em: 28/09/2020 